\title{
A minimum income for healthy living
}

\author{
J N Morris, A J M Donkin, D Wonderling, P Wilkinson, E A Dowler
}

\begin{abstract}
Background-Half a century of research has provided consensual evidence of major personal requisites of adult health in nutrition, physical activity and psychosocial relations. Their minimal money costs, together with those of a home and other basic necessities, indicate disposable income that is now essential for health.

Methods-In a first application we identified such representative minimal costs for healthy, single, working men aged 18-30, in the UK. Costs were derived from ad hoc survey, relevant figures in the national Family Expenditure Survey, and by pragmatic decision for the few minor items where survey data were not available.

Results-Minimum costs were assessed at $£ 131.86$ per week (UK April 1999 prices). Component costs, especially those of housing (which represents around $40 \%$ of this total), depend on region and on several assumptions. By varying these a range of totals from $£ 106.47$ to $£ 163.86$ per week was detailed. These figures compare, 1999, with the new UK national minimum wage, after statutory deductions, of $£ 105.84$ at $18-21$ years and $£ 121.12$ at $22+$ years for a 38 hour working week. Corresponding basic social security rates are $£ 40.70-£ 51.40$ per week.

Interpretation-Accumulating science means that absolute standards of living, "poverty", minimal official incomes and the like, can now be assessed by objective measurement of the personal capacity to meet the costs of major requisites of healthy living. A realistic assessment of these costs is presented as an impetus to public discussion. It is a historical role of public health as social medicine to lead in public advocacy of such a national agenda. (F Epidemiol Community Health 2000;54:885-889)
\end{abstract}

This study was triggered by the innovation in the UK of a statutory minimum wage. During intensive preliminary discussion of it there was virtually no reference to health needs that such an income should be capable of meeting. We seek to rectify this as a contribution to public health.

Half a century of research has provided consensual evidence of major requisites of adult health, and lower disease and death rates, particularly in nutrition, physical activity and psychosocial relations. These, together with standard attitudes to what otherwise is decent and necessary, can now be recognised as an objective basis for personal health. As yet, however, society has adapted little to this modern knowledge.

We have assessed minimal costs in the UK of such healthy living, selecting single young men, a relatively defined group, to establish the principle and to ease our initial foray into what we foresaw would be a difficult field; and also because they are a national priority of concern.

As will be illustrated, a huge volume of research at population and individual levels has been coalescing on conditions of health and wellbeing, on physiological status, risk factors and the prevention of disease, on morbidity and mortality. Equally remarkable, is the consensus of recommendations on lifestyles for the population at large that is flowing for the first time and with increasing consistency and confidence from this modern knowledge, and the specific guidance that, indeed, is now often given by government itself. ${ }^{1-3}$ From the perspective of public health, the possibility of meeting these needs should also be a major consideration of officially approved income policies. Be that as it may, there can be no questioning the duty of public health to disseminate the current consensus of scientific evidence - and to begin to price its application.

\section{Methods}

We were concerned with single healthy men, 18 to 30 years, living away from their family and on their own. Throughout we sought to identify cautious pragmatic, representative minimal costs per week in the UK. We used several sources. For diet, we used a direct survey.

For exercise costs and some other components, we made ad hoc enquiries of official sources to determine inexpensive prices that would meet the defined needs (denoted below by an asterisk).

For most other items, including housing, we used data from the national Family Expenditure Surveys (FES) ${ }^{45} 1994 / 5$ and $1995 / 6$ on the actual expenditure of households of nevermarried working men aged 18-30. Our figures are based on the third of such households with the lowest income per person. These 63 households contained an average of $1.17 \mathrm{men} /$ household (range 1-4), and had an average gross income of $£ 159.99 /$ week. We divided mean weekly household expenditure on any particular item by 1.17 to give cost per person.

Finally, for a few minor but essential items, where direct survey data were not available, we agreed a minimal figure based on such information as was available (denoted below with two asterisks). These summed to $4 \%$ of the total costs.

Costs have been corrected for inflation since the time of data collection using the apposite 
component of the Retail Prices Index. ${ }^{6}$ They are expressed at April 1999 prices.

NUTRITION, DIET (1)

There is overwhelming evidence of the role of food and nutrition in the maintenance and promotion of good health, from the avoidance of classic deficiency diseases ${ }^{7}$ to the role of antioxidants in the prevention of coronary heart disease ${ }^{8}$ and cancer. ${ }^{910}$ Consensual dietary guidelines ${ }^{8911}$ recommend, for example, no more than $35 \%$ of total dietary energy from fat; a polyunsaturated/saturated fat ratio $>0.45$; $<10 \%$ of dietary energy from non-intrinsic sugars; at least five portions of fruit and vegetables ( $400 \mathrm{~g}$ ) excluding potatoes a day; 24 grams of non-starch polysaccharides a day; and two portions of fish a week, one of them oily. In addition, there are dietary reference values for major vitamins and minerals.

We estimated the costs of achieving these recommended intakes by using data from a detailed survey of shops in a very deprived area of London. These costs were assessed for a man of 18-30 years, weighing $69 \mathrm{~kg}$, of average height $(1.75 \mathrm{~m})^{12}$ and body mass index 22.5. We selected foods that are commonly consumed by low income groups of the general UK population. ${ }^{13}$ The diet provides $2771 \mathrm{kcal} /$ day, $221 \mathrm{kcal}$ higher than the Estimated Average Requirement (EAR) for men aged $19-50^{7}$ as, though typically in a "light" job, he is active in recreation. This is consistent with weight regulation.

Two sets of costs that meet these nutritional requirements are shown (table 1): those based on all 205 local shops, excluding superstores, selling food within the survey area; and those of the cheapest superstore in the same area. They reflect common variations in local food prices; those without access to competitively priced shops may have to pay more..$^{13}$

We inflated costs by $6 \%$ to reflect usual nonconsumption of purchased foods, ${ }^{15}$ and have added $£ 1.80$ /week for store cupboard ingredients such as tea and coffee (FES data).

According to the UK National Food Survey, men aged 15-26 who earn less than $£ 150$ /week consume an average of $311 \mathrm{kcal}$ per day outside the home ${ }^{13}$ : cost is $£ 11.42$ (1999 prices) per week, of which $£ 5.30$ would typically be for alcohol. These non-home consumption outlays

Table 1 Food, the healthy diet

\begin{tabular}{lcc}
\hline & Mean cost (£/week) + if bought from: \\
\cline { 2 - 3 } & Local shops & $\begin{array}{l}\text { Cheapest local } \\
\text { superstore }\end{array}$ \\
\hline Bread, breakfast cereals, pasta and rice & 3.13 & 1.33 \\
Potato and potato products & 1.28 & 0.85 \\
Fruit & 1.80 & 1.56 \\
Vegetables & 1.62 & 0.97 \\
Meat and poultry & 3.41 & 2.54 \\
Fish & 1.39 & 0.82 \\
Dairy products, eggs, fats & 5.61 & 3.46 \\
Total, food eaten in home & 18.24 & 11.53 \\
Food not consumed (6\%) ${ }^{14}$ & 1.09 & 0.69 \\
Store cupboard ingredients (FES data) & 1.83 & 1.83 \\
Food and drink consumed outside the home & 11.42 & 11.42 \\
Total & 32.58 & 25.47 \\
\end{tabular}

+Based on data from a deprived area of London, with same groceries purchased from up to 205 local shops (small supermarkets, discount shops, garage forecourts, specialist shops and newsagents), or a local superstore, April 1999 prices. $\ddagger$ See reference 13. are important, acknowledging the role of food and alcohol as a medium for social interaction. The alcohol costs translate into an average of $62 \mathrm{kcal}$ a day, equivalent to less than half the "approved" weekly maximum of 21 units. ${ }^{16}$

The cost of a healthy diet would therefore be $£ 25.47$ or $£ 32.58$ per week in total, depending on access to a competitively priced superstore. We used the mean of these two figures $(£ 29.03)$ in our final calculation.

EXERCISE, PHYSICAL FITNESS, RECREATION (2)

Hopefully, the man will be active and enjoy a lot of walking, in comfortable shoes and away from traffic. Such exercise is rewarding in mental refreshment, in sociality, and weight regulation with its multiple short and long term metabolic benefits. ${ }^{17}$ On average, however, at such young ages, walking cannot be vigorous enough to exceed the $50 \%$ of maximum oxygen uptake, $65 \%$ of maximum heart rate, needed to improve and maintain aerobic health related fitness, wellbeing and multiple physical gains. ${ }^{18} 19$

A choice of least expensive popular dynamic aerobic recreational sports is therefore budgeted: either jogging or fast cycling, whichever is preferred, on three or more days a week and sustained for at least 20 minutes. ${ }^{20}{ }^{21}$ Minimal weekly expenditure for trainers, etc ${ }^{\star}$ or for purchase (annualised) of a reasonably geared lightweight bicycle and its maintenance, plus helmet and $\mathrm{kit}^{13}$ averages $£ 1.54$ a week. ${ }^{\star \star}$

Swimming vigorously, three times a week, again for spells of at least 20 minutes, is also offered as a further alternative especially in bad weather, and like jogging and cycling, in company if desired. Cost: $3 \times £ 1.60$ for enrolled local residents in the London boroughs and provincial cities that we consulted. Budgeted minimally for one week in four, this would come to $£ 1.60$ /week over the year, including kit. *

Muscle strength resistance training (for example, "weights") could also be encouraged (friends, competition, self image, metabolic gains). But no allowance has been included for it.

Minimal cost therefore averages $£ 3.14$ /week. These activities should assure adequate regular aerobic exercise, and "listening to the body" with few if any side effects. ${ }^{21}$ As with the healthy diet, today's consensus is also on the need in youth to establish attitudes and habits-here of exercise and fitness ${ }^{19}{ }^{20}$ - that will matter increasingly as middle age approaches and over the lifetime..$^{22-24}$

HOUSING (3)

Housing is discussed in Saving lives, ${ }^{1}$ but in general less attention is being given to the health impact of housing compared with that of other major factors. But its importance is undeniable both for physical protection and psychosocial wellbeing ${ }^{25}$ ("home" as well as shelter). Overcrowding, poor cleanliness, and inadequate food preparation facilities predispose to diarrhoea and other communicable diseases ${ }^{27}$ damp and mould are associated with respiratory symptoms ${ }^{28-30}$; inadequate heating 
with vulnerability to excess winter death; and indoor air is an important source of exposure to solvents, nitrogen oxide, carbon monoxide, asbestos fibres, radon and other pollutants, including biological allergens. ${ }^{31}$ Noise and poor sound insulation reduce privacy and may have a nuisance impact.

Regrettably, there are few data that allow the (large) cost of housing to be estimated in relation to health criteria. Our figures (table 2) are therefore based on average actual expenditure for the relevant age and income group, but we know that a disproportionate number of low income people live in dwellings of unsatisfactory condition. Some 1.5 million homes are considered unfit for human habitation because of disrepair or inadequate facilities for the hygienic preparation of food. ${ }^{32}$

Thus, the costs of accommodation meeting required standards for health are likely to be higher than those quoted. Costs are also substantially higher for privately rented than for public housing, and they vary almost twofold across regions. Table 2 figures are therefore overestimates for some and underestimates for others, notably London.

OTHER COSTS OF LIVING (4)

The NHS of course provides medical care, and apart from an occasional prescription and the annual dental examination, there are generally no charges. These and other essential living costs are outlined in table 3. Some of the items listed in the table, such as personal care and clothing, have combined importance by both meeting physical needs and contributing to social integration.

SOCIAL INTEGRATION, SUPPORT NETWORKS ${ }^{33-35}(5)$ Lifestyles described in components (1) to (4) have included requisites for "social inclusion". Conventionally, the touchstone of this is work - that is, full time study or a paid job with training. Both demand social interaction, sharing, cooperating.

Some expenses are now specified, table 4, entailed directly in social participation, leading to personal wellbeing, good health - and at the same time to social cohesion, social capital. Group membership, mutual obligations, social roles, communicating, time, merely getting about, all realistically incur money costs, possibly multiple and recurrent, that vary with social class and may lose out with declining income. ${ }^{36-39}$

These relationships generate the bonds, extending from family and the interpersonal to wider networks of reciprocal attachment and

Table 2 Housing

\begin{tabular}{lr}
\hline & \\
Rent (including Council Tax and water charges) & flweek \\
Repairs and redecoration & 0.54 \\
Contents insurance & $\star 1.17$ \\
Fuel & 5.41 \\
Total gross housing costs & 52.21 \\
Average housing and Council Tax benefits & -5.41 \\
Total net housing costs & 46.80 \\
\hline
\end{tabular}

†"Regional" variations from averages of $£ 35.40$ (Wales) to £65.83 (Greater London). Data from the Family Expenditure Survey (FES) ${ }^{4}$ except insurance. ${ }^{\star}$
KEY POINTS

- Modern research provides consensual evidence defining the major personal requisites for health in nutrition, physical activity and psychosocial relations.

- Minimal costs of these plus a home and other necessities are assessed for a single young working man in the UK in 1999.

- The total, $£ 131.86$ per week, is compared with current statutory minimum wages and social security benefits.

- Public health, as social medicine, has to engage in such application of knowledge for the welfare of the population.

affection that foster emotional growth, emotional and physical health, longevity. A widening range of physiological processes, cardiovascular perhaps most notably, are being associated with this personal-social environment, the most "modern" of the requisites for health and prevention being considered. ${ }^{40-43}$ "The good life is through love and work."

\section{SENSITIVITY ANALYSIS}

The total of the five component costs, and their sensitivity to a few key assumptions, are shown in table 5. Region/country of residence, access to supermarkets, and the scope of the fitness regimen are important determinants. For example, a young man living in Wales, close to a cheap supermarket, having a limited exercise programme and generally very low outgoings, could perhaps "live healthily" on $£ 106 /$ week (net). On the other hand, living in London, depending on local shops, with an optimal

Table 3 Other costs of living

\begin{tabular}{lr}
\hline & $£ /$ week \\
Health — direct & 0.04 \\
NHS prescriptions & $\star \star 1.00$ \\
Over the counter medicines and contraceptives & $\star 0.09$ \\
Dental check up & 3.22 \\
Holidays & \\
Personal care & 1.24 \\
Toiletries, soap, toothpaste, etc & 0.25 \\
Hairdressing, etc & \\
Clothes and footwear & 4.97 \\
Outerwear & 0.75 \\
Underwear and accessories & 2.79 \\
Footwear & \\
Household goods and services & 2.63 \\
Equipment, including bedding & 0.86 \\
Cleaning, laundry, repairs, etc & 10.27 \\
Fares on public transport (work and leisure) & $\star \star 3.00$ \\
Savings & $\star 2.59$ \\
Non-state pension contribution (2\% of net income) $\dagger$ & 33.70 \\
Total &
\end{tabular}

Data from FES except *. †Occupational Pensions Advisory Service (personal communication, 1999).

Table 4 Social, cultural, psychosocial integration

\begin{tabular}{lr}
\hline & $£ /$ week \\
TV rental† and licence & $\star 3.80$ \\
Books, magazines & 1.33 \\
Telephone rental and calls & 2.24 \\
Stationery, postage & 0.51 \\
Sports and social club subscriptions & 0.40 \\
Cinema, theatre, concerts, discos etc & 2.39 \\
Sociality at work & $\star \star 0.20$ \\
Trade Union dues $\dagger$ & ${ }^{\star} 1.91$ \\
Gifts, including charity & $\star \star 1.00$ \\
Total & 13.78 \\
\hline
\end{tabular}

Data from FES except ${ }^{\star}$ and ${ }^{\star \star}$. + Varies; a low figure. 
Table 5 Possible range of a minimum income for healthy living in flweek

\begin{tabular}{lccc}
\hline Component & $\begin{array}{l}\text { Lower } \\
\text { estimates }\end{array}$ & Baseline $\neq$ & $\begin{array}{l}\text { Higher } \\
\text { estimates }\end{array}$ \\
\hline Nutrition & 25.47 & 29.03 & 32.58 \\
Physical fitness & 1.54 & 3.14 & 8.14 \\
Housing & 40.92 & 52.21 & 71.35 \\
Other costs of living & 25.61 & 33.70 & 34.08 \\
Social integration & 12.93 & 13.78 & 17.43 \\
Total & 106.47 & 131.86 & 163.58 \\
\hline
\end{tabular}

¥As presented in tables 1 to 4 and in component (2). †Lower estimate assumptions: expenditure data from lowest fifth of FES $(n=38)$, residence in Wales, food bought in cheapest store, no swimming. \$Higher estimate assumptions: expenditure data from the bottom half of FES ( $n=96)$, residence in London, food bought in local shops, two weight training sessions per week at local authority gymnasium.

fitness regimen, and more generous outgoings, he would find it difficult to keep his total spending below $£ 163$ week.

POSSIBLE PERSONAL MARGIN

When deriving our costs we were unable to agree a minimal figure for a "personal margin". Missing thus are any costs for refreshing computer skills, literacy and numeracy, should these not be put right at work. There is no allowance for contingencies such as an eye test when needed, or for emergencies. If he lives in the country, his bicycle could be inadequate.

Neither have we allowed for personal tastes, hobbies, individuality and enthusiasms that have not been covered in the "necessities" of (1) to (5), yet are so much entailed in quality of life. The "social integration" costs quoted in table 4 may be altogether too conservative; they do not, for example, allow for newspapers or for attending even one football match. Reciprocal arrangements with women friends are too variable to call. (Of course there is no allowance for smoking.)

To the extent that all such "marginal" components are omitted, our budget underestimates minimal costs for healthy living.

\section{Discussion}

A project in evidence-based public health is reported.

Our "minimum cost of healthy living" for single young men is assessed at $£ 131.86 /$ week (UK 1999).

This figure does not allow for a personal margin (or for possible housing or Council Tax benefits). In today's society, the disposable income that could meet this minimal cost may be posited as a necessary pre-condition of health.

Pay from the new national minimum wage (in April 1999), $£ 3.00$ an hour at $18-21$ years and $£ 3.60$ at 22 years plus translates into disposable weekly income of $£ 105.84$ and $£ 121.12$, respectively, for a 38 hour working week after statutory tax and social security deductions. At 18-21, 51 hours, and at 22 plus 42.5 hours would have to be worked to earn the income needed to meet our assessed minimum costs of healthy living.

On basic social security, the jobseeker's allowance at ages $18-24$ is $£ 40.70$ /week and $£ 51.40$ at 25 years and over (again April 1999).
Questions will arise about some of our inclusions. We are not concerned with subsistence and the waste of human potential that entails. On the other hand, though there are bearings throughout, our treatment of mental health for example is limited; and there are of course other needs for health additional to the cluster we considered. ${ }^{45}$ Variations of lifestyles by socioeconomic status and ethnicity, too, have been disregarded. All these other factors contribute to observed gradients between income and health. ${ }^{46}{ }^{47}$ However, this does not detract from the importance of an absolute minimal income based on health knowledge.

The data assembled could be made more representative (for example, with personal margin) by comprehensive field sample survey, and extended to more complex groups, for example, mothers and children and the elderly. We sought to establish a principle and pragmatically selected a relatively simple case.

Gains in population health may be hoped from such an initiative on unmet needs and inequity, so some reduction of inequalities in health could follow. ${ }^{46-48}$

Our approach is traditional "public health", ${ }^{49}$ which traces back also to Rowntree at the beginning of the century, ${ }^{50}$ to the British Medical Association's estimates in the 1930s of the cost of a minimum diet "if health and working capacity are to be maintained", ${ }^{51}$ and to Boyd Orr's Food Health and Income. ${ }^{52}$ There are current official approaches in other countries, for example, Norway, Sweden, to minimal acceptable living standards that allow for the cost of the defined healthy diet. ${ }^{53}$

Society, including social welfare, has been slow in coming to terms with the new health knowledge. (Smoking is a special issue and outwith our terms of reference.) We can now begin to measure standards of living, minimum official incomes, "equality of opportunity", poverty and the like by the capacity to afford generally accepted and specific essential requisites of healthy living. Assessments such as those attempted here could become an objective non-relative referent. This would be different from the relative assessment of poverty, for example, based on $50 \%$ of average income..$^{55}$

It is beyond our remit to consider the practicalities, financial and other, of any such message for social policies. Affordable housing and the availability of food evidently are critical. ${ }^{5657}$ And society will of course also require massive efforts in public education and motivation to reap the benefit of such increasing opportunities for choosing health.

For public health to return to its roots as social medicine ${ }^{58}$ : taking positive stock of scientific advance; translating this into standards of living necessary for health; and giving a lead for it in public advocacy for the whole of the population could mark a beginning of its overdue renewal.

We thank the London School of Hygiene and Tropical Medicine's UK Health Policy Group (chair: Professor M ColeMedicine's UK Health Policy Group (chair. Professor M Coleman), and are greatly obliged to the Low Pay Unit for the data on the National Minimum Wage and Social Security. 
Contributors

JM designed the study and drafted much of the text. AD and ED contributed the nutrition component, $1 ; \mathrm{JM}, 2$ and 5; PW, 3; and
DW, who was also responsible for analysing the FES and RPI data, 4. All authors shared in the final formulation and text.

Funding: the dietary study was funded by North Thames NHS Executive, ICA 12, who permitted publication of the data on food prices. The Academic Initiative Fund of the London School of Hygiene and Tropical Medicine defrayed running costs.

Conflicts of interest: none.

\section{Addendum}

Update of principal figures, June 2000.

Minimum income for healthy living: $£ 136.66$ per week. (Uprated by Retail price index).

National minimum wage, disposable income: $£ 112.30 \mathrm{pw}$ at $18-21$ years. $£ 122.64$ pw at 22 years plus. (Uprated for statutory deductions and increase of NMW at 18-21 years by $20 \mathrm{p}$ an hour).

Fobseeker's allowance; $£ 41.35$ at $18-24$ years. $£ 52.20$ at 25 years plus.

1 Saving lives: Our Healthier Nation. Cm 4386. London: The Stationery Office, 1999

2 National Health Service Executive. The NHS Home Healthcare Guide. Leeds, 1998

3 Health Education Authority. Eight guidelines for a healthy diet. London: Ministry of Agriculture, Fisheries and Food, and Department of Health. 1997.

4 Family Spending. A Report on the 1998-99 Family Expenditure Survey. London: Stationery Office, 1999.

5 Banks J, Johnson P, eds. How reliable is the Family Expenditure Survey? London: Institute of Fiscal Studies, 1998.

6 Retail Prices Index: Business Monitor MM23. London: Office for National Statistics, Oct 1996 and April 1999.

7 Department of Health. Dietary reference values for food energy and nutrients for the United Kingdom. Report on Health and and nutrients for the United Kingdom. Report on Health and
Social Subjects No. 42. Report of the Panel on Dietary Social Subjects No. 42. Report of the Panel on Dietary
Reference Values of the Committee on Medical Aspects of Reference Values of the Committee

8 Department of Health. Nutritional aspects of cardiovascular disease. Report of the Cardiovascular Review Group of the Committee on Medical Aspects of Food Policy. London: HMSO, 1994

9 World Cancer Research Fund/American Institute for Cancer Research. Food nutrition and the prevention of cancer: a global perspective. Menasha, USA: BANTA Book Group, 1997.

10 Department of Health. Nutritional aspects of the development of cancer. Report on health and social subjects. No 48 . London: The Stationery Office, 1998.

11 Diet, nutrition and the prevention of chronic diseases. Geneva: WHO, 1990.

12 Office of Population Censuses and Surveys. The Dietary and Nutritional Survey of British Adults. London: HMSO, 1990.

3 Donkin AJM, Dowler EA, Stevenson SJ, et al. Mapping Donkin AJM, Dowler EA, Stevenson SJ, et al. Mapping
access to food at a local level. Br Food f 1999;101:554-62.

4 Piachaud D, Webb J. The price of food: missing out on mass Piachaud D, Webb J. The price of food: missing out on mass consumption. STICERD Occasional Paper 20. London:

15 Wenlock RW, Buss DH, Deny BJ, et al. Household food wastage in Britain. B $\mathcal{F}$ Nutr 1980;43:53-70.

16 Department of Health. Sensible drinking. Report of an Interdepartmental Working Group. London: 1995.

17 Morris JN, Hardman AE. Walking to health. Sports Med 1997;23:306-32.

18 Bouchard C, Shephard RJ, Stephens T. Physical activity, fitness and health. Consensus statement. Champaign, IL: Human Kinetics, 1993.

19 Sidney S, Sternfield B, Haskell WL, et al. Seven-year change in graded exercise treadmill test performance in young adults in the CARDIA study. Med Sci Sports Exerc 1998;30: 427-33.

20 Physical activity and health: A report of the Surgeon General. US Department of Health and Human Services, Centers for Disease Control and Prevention, National Center for Chronic Disease Prevention and Health Promotion, Atlanta: 1996:61-87.

21 American College of Sports Medicine. Fitness book. 2nd ed. Champaign, IL. Human Kinetics, 1998.

22 Morris JN. Exercise in the prevention of coronary heart disease: today's best buy in public health. Med Sci Sports Exerc 1994;26:807-14.
23 Paffenberger RS, Lee I-Min. A natural history of athleticism, health and longevity. $\mathcal{F}$ Sports Sci 1998;16:SR31-45. 24 Gaziano J. When should heart disease prevention begin? $N$ Engl f Med 1998;338:1690-2.

25 Lowry S. Housing and health. London: British Medical Journal, 1991

26 Kasl SV. Quality of the residential environment, health and well-being. Bull NY Acad Med 1990;66:479-90.

27 Perry B. Health promotion in the home: 1. Food poisoning, the link with home hygiene. Professional care of mother and child 1994;4:188-9.

28 Andriessen JW, Brunekreef B, Roemer W. Home dampness and respiratory health status in European children. Clin Exp Allergy 1998;28:1191-200.

29 Burr ML, Anderson HR, Austin JB, et al. Respiratory symptoms and home environment in children: A national survey. Thorax 1999;54:27-32.

30 Peat JK, Dickerson J, Li J. Effects of damp and mould in the home on respiratory health: a review of the literature. Allergy 1998;53:120-8.

31 Samet JM, Spengler JD, eds. Indoor air pollution. A health perspective. Baltimore: Johns Hopkins University Press, 1991.

32 Best R. The housing dimension. In: Benzeval M, Judge K, Whitehead M. Tackling health inequalities. An agenda for action. London: King's Fund, 1995.

33 Cassel J. The contribution of the social environment to host resistance. Am $\mathcal{F}$ Epidemiol 1976;104:107-23.

34 Brown GW, Harris T. Social origins of depression. London: Tavistock, 1978

35 Berkman LF, Syme ST. Social networks, host resistance and mortality. Am F Epidemiol 1979;109:186-204.

36 Kawachi I, Kennedy BP. Health and social cohesion: why care about income inequality? BMF 1997;314:1037-40.

37 Wilkinson RG. Comment: Income, inequality, social cohesion. Am f Public Health 1997;87:1504-6.

38 Putnam RD. Bowling alone: America's declining social capital. Fournal of Democracy 1995;6:65-78.

39 McKibbin R. Classes and cultures, England 1918-1951. Oxford: OUP, 1998:84-98, 188-205.

40 Berkman LF. The role of social relations in health promotion. Psychosom Res 1995;57:245-54.

41 Cohen S, Doyle WJ, Skoner DP, et al. Social ties and susceptibility to the common cold. $\mathcal{F A M A} 1997 ; 277: 1940$ 4.

42 Dalgard OS, Haheim LL. Psychosocial risk factors and mortality: a prospective study with special focus on social support, social participation, and locus of control in Norway. 7 Epidemiol Community Health 1998;52:476-81.

43 Brunner E. The social and biological basis of cardiovascular disease in office workers. In: Blane D, Brunner E,
Wilkinson R, eds. Health and social organization: towards health policy for the 21st century. London: Routledge, 1996: health policy

44 Freud S (imputed). F Am Psychoanalytic Assoc 1977;25:37.

45 Bosma H, Marmot MG, Hemingway H, et al. Low job control and risk of CHD in Whitehall II. BMF 1997;314:55865

46 Aylin P, Dunnell K, Drever F. Trends in mortality of young adults aged 15-4 years in England and Wales. Health Statistics Quarterly 1999; Spring:34-9.

47 Blane D, Bartley M, Davey Smith G. Disease aetiology and materialistic explanation of socioeconomic mortality differentials. Eur f Public Health 1997;7:385-91 and 1998;8: 183-4.

48 Department of Health. Report of Independent Inquiry into Inequalities in Health. London: Stationery Office, 1998:4753

49 Hamlin C. Public health and social justice in the age of Chadwick. Cambridge: CUP, 1998

50 Harris B. Seebohm Rowntree and the measurement of poverty, 1899-1951. In: Bradshaw J, Sainsbury R, eds. Getting the measure of poverty. Aldershot: Avebury, 2000.

51 Drummond JC, Wilbraham A, Hollingsworth D. The Englishman's food. London: Jonathan Cape, 1957:446-7.

52 Orr JB. Food, health and income. London: Macmillan, 1936.

53 Taboas C, Simpson R. Budget standards in different European 24 .

54 Oppenheim C, ed. An inclusive society. Strategies for tackling poverty. London: Institute for Public Policy Research, 1998:61-9.

55 Veit Wilson J. Setting adequacy standards. How governments define minimum incomes. Bristol: The Policy Press, 1998.

56 Leather S. The making of modern malnutrition. London: Caroline Walker Trust, 1996.

57 Dowler EA. Food as a utility: ensuring food security for all. Consumer Policy Review 1998;8:162-8.

58 Morris JN. Inequalities in health: ten years and little further on. Lancet 1990;336:491-3. 